\title{
Spinach curly top virus: A Newly Described Curtovirus Species from Southwest Texas with Incongruent Gene Phylogenies
}

\author{
Surendranath Baliji, Mark C. Black, Roy French, Drake C. Stenger, and Garry Sunter
}

First and fifth authors: Department of Biology, University of Texas at San Antonio, San Antonio 78249; second author: Department of Plant Pathology and Microbiology, Texas A\&M University, Uvalde 78802; and third and fourth authors: U.S. Department of AgricultureAgricultural Research Service, University of Nebraska, Lincoln 68583. Accepted for publication 5 March 2004.

\begin{abstract}
Baliji, S., Black, M. C., French, R., Stenger, D. C., and Sunter, G. 2004. Spinach curly top virus: A newly described Curtovirus species from southwest Texas with incongruent gene phylogenies. Phytopathology 94:772-779.

A curtovirus associated with a disease of spinach was isolated in southwest Texas during 1996. Disease symptoms included severe stunting and chlorosis, with younger leaves curled, distorted, and dwarfed. Viral DNA was purified and an infectious clone obtained. Agroinoculation using a construct bearing full-length tandem repeats of the cloned viral genome resulted in systemic infection of species in six of seven plant families tested, indicating that the virus has a wide host range. Symptoms produced in spinach agroinoculated with cloned viral DNA were similar

clone comprised 2,925 nucleotides, with seven open reading frames encoding proteins homologous to those of other curtoviruses. Complete genome comparisons revealed that the spinach curtovirus shared 64.2 to $83.9 \%$ nucleotide sequence identity relative to four previously characterized curtovirus species: Beet curly top virus, Beet severe curly top virus, Beet mild curly top virus, and Horseradish curly top virus. Phylogenetic analysis of individual open reading frames indicated that the evolutionary history of the three virion-sense genes was different from that of the four complementary-sense genes, suggesting that recombination among curtoviruses may have occurred. Collectively, these results indicate that the spinach curtovirus characterized here represents a newly described species of the genus Curtovirus, for which we propose the name Spinach curly top virus.
\end{abstract} to those observed in the field. Viral single-stranded and double-stranded DNA forms typical of curtovirus infection were detected in host plants by Southern blot hybridization. The complete sequence of the infectious
Additional keyword: geminivirus.

In the fall of 1996, a curly top disease epidemic occurred within spinach (Spinacia oleracea L.) production fields in the region surrounding Uvalde, TX. The disease rendered affected spinach plants unsuitable for fresh market and was manifested as stunting and yellowing, with younger leaves distorted, dwarfed, and curled. This economically important disease of spinach has been attributed to Beet curly top virus (BCTV) in both southwest Texas $(7,30)$ and California $(7,20)$. Occurrence of curly top disease during the 1996 southwest Texas epidemic was coincident with presence of the beet leafhopper (Circulifer tenellus (Baker)), the only known curtovirus vector present in North America (1).

The genus Curtovirus of the family Geminiviridae is composed of leafhopper-transmitted viruses that infect dicotyledonous hosts and possess a monopartite circular single-stranded (ss)DNA genome of $\approx 3 \mathrm{~kb}$. Although curtoviruses with different pathogenic phenotypes have been known for over 60 years (1), all were assumed to be strains of BCTV. In the past two decades, sequencing of curtovirus genomes $(3,17,23,40,43,45,52)$ has revealed that four biologically distinct strains of BCTV (49) are sufficiently different from one another to warrant status as separate species (48).

The genus Curtovirus now consists of four species: BCTV, Beet severe curly top virus (BSCTV), Beet mild curly top virus (BMCTV), and Horseradish curly top virus (HrCTV). BCTV retained isolates of the $\mathrm{Cal} / \mathrm{Logan}$ strain, because the California

Corresponding author: G. Sunter; E-mail address: gsunter@utsa.edu

Publication no. P-2004-0511-01R

This article is in the public domain and not copyrightable. It may be freely reprinted with customary crediting of the source. The American Phytopathological Society, 2004. isolate has been in culture the longest among those characterized at the molecular level and was the first to be sequenced (43). The Logan isolate (9) is very similar in sequence (17) and pathogenicity (49) to the California isolate. Aside from these two isolates, curtoviruses still recognized as BCTV have been found only in husbanded virus populations used for sugar beet cultivar assessment $(52)$. The curtovirus isolates CFH $(45,49)$ and Iran $(3)$ are now considered isolates of BSCTV, whereas the Worland $(49,52)$ and W4 (40) isolates are now known as BMCTV. In contrast to BCTV, the curtoviruses BSCTV and BMCTV are widely distributed in the western United States and are commonly found in sugar beet production fields (47,51). Although BCTV, BSCTV, and BMCTV have wide host ranges, HrCTV is distinguished from other curtovirus species based on a narrow host range $(8,49)$ and the recombinant nature of its genome (23), in which the complementary-sense genes $C l$ and $C 4$ are most closely related to the whitefly-transmitted begomovirus Squash leaf curl virus (SLCV).

Unpublished studies conducted in 1996 and 1997 by two of the authors (M. C. Black and D. C. Stenger) confirmed that a curtovirus was associated with the 1996 curly top disease epidemic of spinach in southwest Texas. However, this preliminary diagnosis did not define which curtovirus was involved but did suggest that the virus in question may be a new strain or species. To resolve this issue, we characterized the genomic and biologic properties of the virus. In this article, we present data indicating that a virus recovered from spinach during the 1996 southwest Texas curly top disease epidemic represents a fifth and previously undescribed Curtovirus species that we propose be named Spinach curly top virus (SCTV). Furthermore, we present phylogenetic analyses that demonstrate incongruent evolutionary relationships among individual genes that are most easily explained as having resulted from recombination among curtoviruses. 


\section{MATERIALS AND METHODS}

Collection and analysis of field samples. Forty-eight isolates (individual spinach plants exhibiting curly top disease symptoms) were collected in four counties (Frio, Maverick, Uvalde, and Zavala) during November 1996 from 13 separate fields located within an $\approx 150$-km radius of Uvalde, TX. Total DNA was extracted from each isolate as described (47) and evaluated for the presence of curtovirus DNA by Southern blot hybridization with a full-length, complementary-sense riboprobe of BCTV-Logan that was transcribed using pCT10 as a template (17). Total DNA extracted from asymptomatic spinach leaves purchased at a market served as a negative control. Total DNA samples from isolates that tested positive for curtovirus DNA were digested individually with EcoRI, BamHI, SalI, or XhoI and the products identified by Southern blot hybridization using a full-length virion-sense riboprobe of BSCTV-CFH transcribed from pACFH-R (5).

Cloning of curtovirus DNA. Total DNA samples $(10 \mu \mathrm{g})$ from isolates 1,2 , and 3 (collected from a field located $\approx 16 \mathrm{~km}$ northeast of Crystal City, Zavala County, TX) were digested with EcoRI and size fractionated by electrophoresis in $1 \%$ agarose. Digested DNA, ranging in size from $\approx 2.7$ to $3.2 \mathrm{kbp}$, was recovered and ligated to EcoRI-digested pUC8. The ligation products were used to transform Escherichia coli strain DH5 $\alpha$ and transformants were screened for the presence of curtovirus DNA inserts by colony blot hybridization using a riboprobe transcribed from pCT10. Recombinant plasmids were isolated from clones identified as positive for curtovirus DNA by colony blot hybridization and compared to one another by endonuclease restriction mapping.

Construction and host range of an infectious clone. The plasmid pTU96-3-1, bearing an apparent genomic-length curtovirus EcoRI insert derived from spinach isolate 3, was arbitrarily chosen for further analysis. Tandemly repeated copies of the SCTV genomic DNA were cloned into the binary Ti plasmid vector pMON521 (37) by cleaving pTU96-3-1 with EcoRI, isolating the genomic-length DNA fragment, and ligating with pMON521 cleaved at the EcoRI site. The Ti plasmid construct containing tandemly repeated copies of SCTV DNA was introduced by electroporation into Agrobacterium tumefaciens strain GV3111SE containing the disarmed Ti plasmid pTIB36SE.

The host range of SCTV was examined by agroinoculation of plants with cloned DNA (57). Inoculum was prepared by growing A. tumefaciens, transformed with the pMON521 derivative bearing the tandemly repeated genome of SCTV, for 2 days at $28^{\circ} \mathrm{C}$ in liquid culture. Plant species tested included members of the Chenopodiaceae: spinach cvs. Indian Summer, Bloomsdale, and Viroflay, and sugar beet (Beta vulgaris L.) Beta Seed line 3FF0047; Apiaceae: carrot (Daucus carota L.) cv. Primo Hybrid; Asteraceae: flossflower (Ageratum houstonianum); Brassicaceae: Arabidopsis thaliana Heyn. ecotype Columbia; Cucurbitaceae: pumpkin (Cucurbita maxima Duchesne) cv. Small Sugar; Fabaceae: bean (Phaseolus vulgaris L.) cv. Stringless; and Solanaceae: Nicotiana benthamiana Domin., tobacco (N. tabacum L.) variety Samsun, and tomato (Lycopersicon esculentum Mill.) cv. Beefsteak.

Seedlings were prepared for agroinoculation differently, depending upon the species tested. For bean, seeds were germinated in petri dishes for $24 \mathrm{~h}$ and agroinoculated by pin-pricking the emerging hypocotyls. Four- to five-week-old A. thaliana plants were agroinoculated by needle puncture in the crown of the rosette. Three-week-old flossflower, $N$. benthamiana, tobacco, and carrot plants were agroinoculated by injection into petioles of young leaves. For sugar beet, spinach, tomato, and pumpkin, the shoot tips of 3- to 4-week-old plants were excised and inoculum applied to the cut stem, followed by pin-pricking through the inoculum into the cut stem.

Agroinoculated plants were maintained in a growth chamber (12 $\mathrm{h}$ of light and $12 \mathrm{~h}$ of dark at $24^{\circ} \mathrm{C}$ ) and monitored for the appearance of symptoms. Negative controls consisted of plants mock inoculated with cultures of Agrobacterium tumefaciens bearing pMON521. Symptomatic plant samples were extracted for total DNA 7 to 14 days postinoculation; nonsymptomatic plants were extracted for total DNA 4 to 6 weeks postinoculation. Total DNA samples $(2 \mu \mathrm{g})$ were assayed for SCTV DNA by Southern blot hybridization using the EcoRI insert of pTU96-3-1 labeled with $\left[\alpha^{32} \mathrm{P}\right]-\mathrm{dCTP}$ as a probe. Labeling was accomplished using the DECA Prime II random priming labeling kit (Ambion; Austin, TX).

DNA sequencing and phylogenetic analyses. The curtovirus DNA insert of pTU96-3-1 was completely sequenced on both strands using a "primer walking" strategy employing a combination of universal and custom primers. Automated sequencing was performed by the Plant-Microbes Genomic Facility, Ohio State University, Columbus, $\mathrm{OH}$. The complete nucleotide sequence of SCTV was compiled and genomic coordinates assigned in virionsense with the $3^{\prime}$-proximal $A$ residue adjacent to the replication initiator protein (Rep) nick site (26) designated as nucleotide 1.

Sequence comparisons included all complete curtovirus sequences available in GenBank: SCTV (AY548948), BCTV-Cal (M24597), BCTV-Logan (AY379637), BSCTV-CFH (U02311), BSCTV-Iran (X97203), BMCTV-Worland (U56975), BMCTVW4 (AY13467), and HrCTV (U49907). Several begomovirus DNA A components also were included in some of the analyses: SLCV-E (M38183), Bean golden yellow mosaic virus-Puerto Rico (BGYMV-PR) (M10070), and Tomato yellow leaf curl Sardinia virus (TYLCSV) (X61153). The SLCV-E DNA A sequence (27) included one uncalled $(\mathrm{N})$ base at nucleotide 1,264 (coordinate based on Rep nick site). The DNA A sequence of the closely related $(99.5 \%$ nucleotide sequence identity) SLCV-10 isolate has a $\mathrm{G}$ at this position (J. K. Brown, personal communication); therefore, we assumed that SLCV-E DNA A also has a G at nucleotide position 1,264.

Sequence comparisons were based on alignments of the complete genome or individual genes. For each gene, nucleotide sequences were translated using the standard genetic code. Protein sequences were aligned using the T-Coffee computer program (31). Protein alignments were used as guides to manually align nucleotide sequences with the Sequence Alignment Editor (version 2.0 alpha 11, copyright 1996-2001; A. Rambaut, Department of Zoology, University of Oxford, UK) such that gaps did not occur within codons. Intergenic nucleotide sequences were aligned using Clustal X (59). Sequence identity of SCTV relative to other curtoviruses was calculated for the complete genome (percent nucleotide sequence identity) and for individual genes (percent nucleotide and percent amino acid sequence identity) using MEGA version 2.1 (24) to generate genetic distance matrices, with the output converted to percent identity.

Phylogenetic tree reconstruction was done by Bayesian analysis with Markov chain Monte Carlo (MCMC) sampling as implemented in the computer program Mr. Bayes version 2.01 (21). First, lack of bias in base composition across taxa was determined using the $\chi^{2}$ base frequency test in PAUP* version 4.0b10 (58). The Akaike Information Criterion in Modeltest (35) then was used to determine the best-fit model of evolution in a likelihood framework to ensure that the model employed in tree reconstruction had statistical justification. Parameter optimization of the selected model (generalized time reversible model of sequence evolution plus among-site rate variation) was done for 500,000 cycles in Mr. Bayes, starting with random trees. After 100,000 cycles to allow MCMC sampling to converge on stable likelihood estimates, every two-thousandth tree was sampled (200 trees sampled) to generate a majority-rule consensus tree. The analyses were repeated to provide further confidence that independent MCMC samplings were converging on similar global solutions of likelihoods and parameter values. Phylogenetic analyses of the virion-sense genes $(V 1, V 2$, and $V 3)$ were restricted to curto- 
viruses, because begomoviruses do not have genes homologous to $V 2$ and $V 3$, and because genetic distances separating the $V 1$ (known as $A V I$ or $A R l$ in bipartite begomoviruses) genes of the two genera are large. HrCTV was excluded from analyses of genes $C 2$ and $C 3$ (known as $A C 2$ or $A L 2$ and $A C 3$ or $A L 3$ in the bipartite begomoviruses), because this viral sequence lacks a $C 3$ gene, and the HrCTV C2 open reading frame is not homologous to any known gene. Phylograms were visualized using TREVIEW 1.5.3 (33) and rooted using HrCTV (virion-sense genes) or the Old World begomovirus TYLCSV (complementary-sense genes). Nodes bearing clade credibility values less than $60 \%$ were collapsed to polytomies. Potential recombination sequence junctions among curtoviruses were identified using the LARD computer program (16) as implemented in RDP version 2 (29).

\section{RESULTS}

Curtovirus DNA forms present in field-infected spinach. Of 48 field-collected spinach isolates, 46 tested positive for curtovirus DNA by Southern blot hybridization using a BCTV-Logan riboprobe. The curtovirus-positive isolates were distributed among all 13 spinach fields sampled in the four county area. The viral DNA profiles for three spinach isolates in which ssDNA and double-stranded (ds) supercoiled (SC) or open circle (OC) DNA forms of the virus genome were detected are shown in Figure 1.

Why two isolates did not test positive for curtovirus DNA by Southern blot hybridization was not investigated. It was noted that DNA samples from curtovirus-positive isolates varied in hybridi-

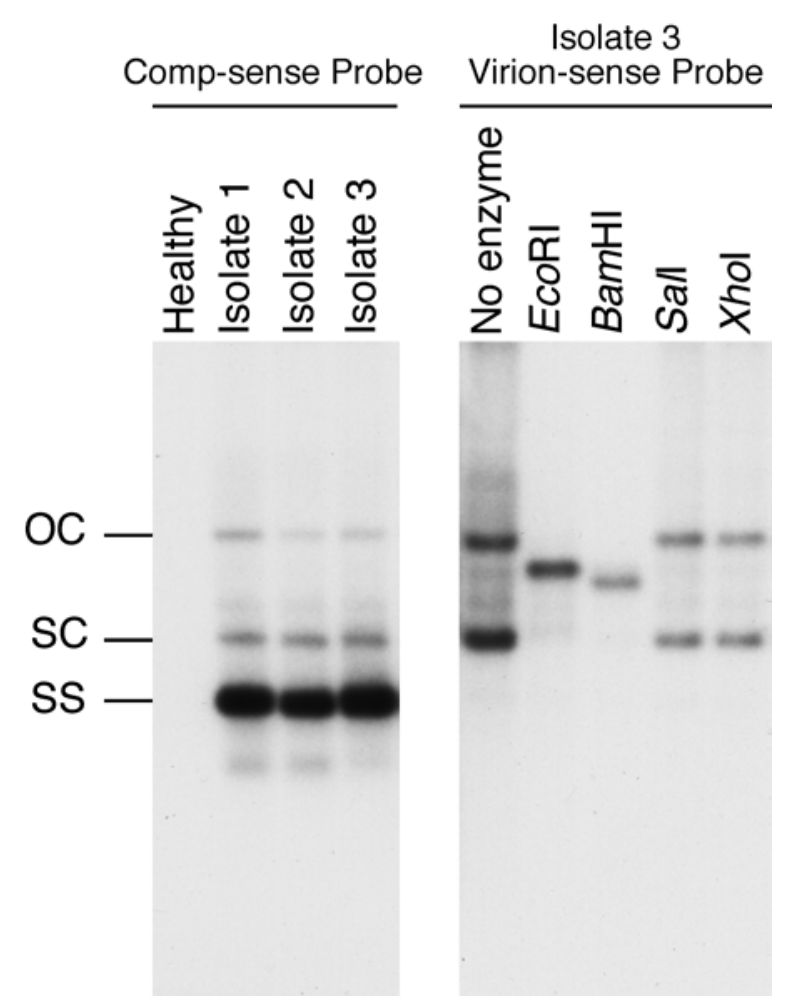

Fig. 1. Curtovirus DNA forms associated with field-collected curly top diseased spinach. Presented on the left is a Southern blot hybridization assay of total DNA samples $(3 \mu \mathrm{g})$ from three diseased spinach isolates $(1,2$, and 3$)$ or asymptomatic store-bought spinach (healthy) probed with a Beet curly top virus-Logan riboprobe of complementary-sense (comp-sense). Presented on the right is a Southern blot hybridization assay of total DNA of isolate 3 incubated with various restriction endonucleases and probed with a Beet severe curly top virus-CFH riboprobe of virion-sense. The relative mobility of viral single-stranded (SS) or double-stranded supercoiled (SC) and open circular (OC) DNA forms are indicated on the left. Note that the complementary-sense riboprobe hybridized to all viral DNA forms, whereas the virion-sense riboprobe hybridized only to double-stranded DNA forms of the viral genome. zation signal strength, ranging from strong (Fig. 1) to weak (data not shown). Thus, it is possible that the two symptomatic yet hybridization-negative isolates contained curtovirus DNA concentrations below the threshold of detection. Alternatively, these two samples may have harbored another viral or nonviral pathogen producing symptoms similar to curtoviruses, as has been noted for Verticillium or Fusarium infection of spinach in California (20).

Three curtovirus-positive isolates ( 1 to 3 , recovered from a field in Zavala County) were digested with various endonuclease restriction enzymes to identify a unique site to linearize viral dsDNA for cloning. All three isolates yielded endonuclease restriction profiles identical to that shown in Figure 1 for isolate 3 , in which EcoRI digestion resulted in a single $\approx 2.9$-kbp linear product. SalI and XhoI did not alter the electrophoretic mobility of viral SC and OC dsDNA, suggesting that sites cleaved by these enzymes were not present in the viral genome. Digestion with Bam HI resulted in a single $\approx 2.6-\mathrm{kbp}$ linear product (Fig. 1). This result was interpreted as indicating that the viral genome contained two BamHI sites located $\approx 300$ bp apart, and that the smaller fragment (which shared $85 \%$ nucleotide identity with the probe) yielded a hybridization signal too weak to be detected in the assay.

Characterization of the SCTV genome. Recombinant plasmids containing $\approx 2.9$-kbp curtovirus EcoRI inserts were obtained for isolates 1, 2, and 3. Endonuclease restriction mapping (data not shown) of six clones from isolate 1, two clones from isolate 2 , and one clone from isolate 3 produced identical results for all nine clones with respect to the number and relative locations of BamHI, BstXI, Csp45I, HindIII, KpnI, SacI, SnaBI, and XbaI cleavage sites within the curtovirus DNA inserts. Two BamHI sites separated by $\approx 2,600$ bp were present in each cloned viral DNA insert. None of the nine viral DNA inserts contained ApaI, $P v u I I, S a l I, S c a I$ SpeI, or XhoI cleavage sites. Collectively, these results indicated that all nine clones examined from the three isolates represent very closely related curtovirus genomes that share an endonuclease restriction map distinct from that of $\approx 150$ full-length clones derived from 65 curtovirus isolates examined in a previous study (51).

One clone (pTU96-3-1), derived from isolate 3, was arbitrarily selected for further analysis. The nucleotide sequence of the curtovirus insert of pTU96-3-1 was determined to be 2,925 bp. The genome organization of SCTV (Fig. 2) was typical of most curtoviruses, with three overlapping genes (V1,V2, and V3) present in the virion-sense strand and four overlapping genes $(C 1, C 2$, $C 3$, and $C 4$ ) present in the complementary-sense strand. Studies using BCTV-Cal $(4,25,42,44)$, or BCTV-Logan $(17,18,56,57)$ indicate that all seven curtovirus genes are functional.

The SCTV genome was examined for cis-acting elements involved in replication and gene expression. The small intergenic region (nucleotides 1,327 to 1,346), located between the converging $V 1$ and $C 3$ genes, contained $\mathrm{A} / \mathrm{T}$ rich polyadenylation signals. The large intergenic region (nucleotides 2,840 to 268) contained sequence elements characteristic of the geminivirus DNA replication origin (ori) (12). This region contained the highly conserved stem-loop structure (nucleotides 2,902 to 16) that includes the Rep nick site (TAATAT $\downarrow$ AC) where rolling circle replication is initiated (26). The Rep binding site (GGTGCTTTGGGAG), conferring replication specificity in begomoviruses (11) and curtoviruses $(6,48)$, was located adjacent to the stemloop at nucleotides 2,876 to 2,888 . The large intergenic region also contained potential promoter elements. In BCTV-Cal, fine mapping of virion-sense mRNAs revealed three $3^{\prime}$-coterminal RNAs with 5'-termini suitably positioned relative to each virionsense gene and downstream of two TATA boxes (13). Although the mRNAs of SCTV have not been mapped, TATA boxes at SCTV nucleotides 233 to 238 (TATATA), nucleotides 264 to 269 (TATAAA), and nucleotides 437 to 441 (TATAT) represent poten- 
tial promoter elements for a series of $3^{\prime}$-coterminal virion-sense transcripts. Less is known concerning complementary-sense transcription in curtoviruses. However, based on analogy with begomoviruses (55), the SCTV sequence (TATTTAA in the complementary-sense) located between the stem-loop and the Rep binding site at nucleotides 2,898 to 2,892 may represent an element of the $\mathrm{C} 1$ promoter.

Infectivity and host range of cloned SCTV DNA. An experimental host range of SCTV is presented in Table 1. Agroinoculation of three spinach cultivars resulted in severe disease symptoms resembling those observed in the field and in plants inoculated by viruliferous leafhoppers bearing progeny virus

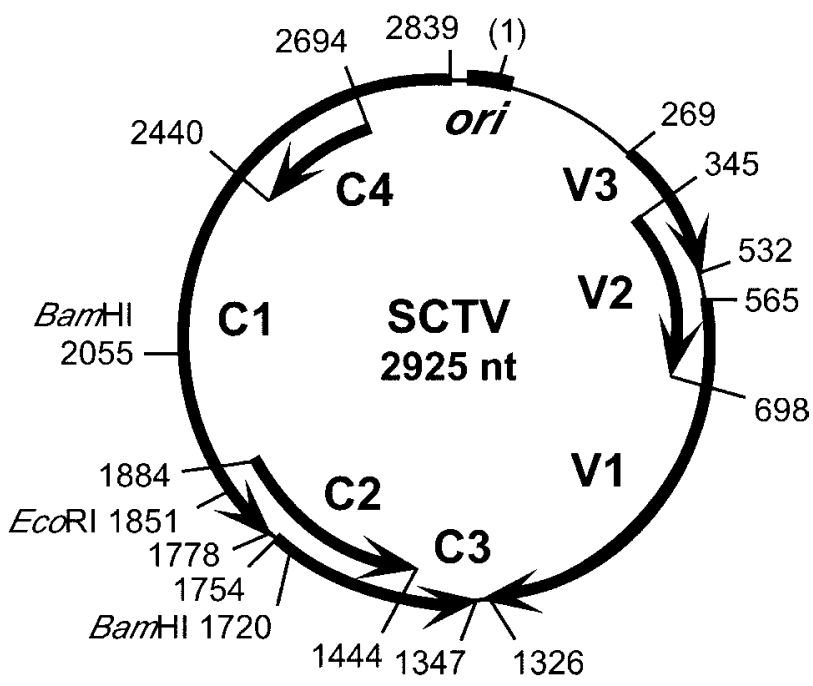

Fig. 2. Genome organization of Spinach curly top virus (SCTV). The solid arrows denote the location and polarity of genes present in virion-sense $(V I$, $V 2$, and V3) or complementary-sense ( $C 1, C 2, C 3$, and $C 4)$. V1 encodes the capsid protein, $V 2$ encodes a regulator of single-stranded and double-stranded DNA accumulation, V3 encodes a protein required for efficient systemic movement, $C 1$ encodes the replication initiator protein (Rep), $C 2$ encodes a pathogenesis-enhancement protein, $C 3$ encodes a replication enhancer protein, and $C 4$ encodes a regulator of the host cell cycle. Sequences within the large intergenic region containing elements of the DNA replication origin (ori) are indicated as an arc. Nucleotide coordinates are given in virion-sense, with nucleotide 1 defined as the A residue located $3^{\prime}$ of the Rep protein nick site of the ori. The location of the EcoRI site used to linearize viral doublestranded DNA for cloning and the locations of the two BamHI sites flanking the small fragment not detected by Southern hybridization in Figure 1 are indicated. derived from cloned DNAs of BCTV, BSCTV, and BMCTV (49). Symptoms observed in sugar beet were those typical of curly top disease produced by BCTV or BSCTV in highly susceptible sugar beet cultivars $(9,49)$. Agroinoculation of $N$. benthamiana and Arabidopsis thaliana with SCTV resulted in severe symptoms in both hosts most similar to those produced by BSCTVCFH $(28,50)$. Although agroinoculation of beans and carrot was less efficient compared with other experimental hosts, symptoms produced in these hosts resembled those reported for curtovirus infection $(1,20,49)$. SCTV did not infect tomato or tobacco, two hosts known to be susceptible to BCTV, BMCTV, and BSCTV $(1,43,49,54)$.

SCTV DNA forms detected by Southern blot hybridization of representative DNA samples from each experimental host identified in Table 1 are shown in Figure 3. Hybridization signal strength varied among infected hosts, ranging from strong in spinach, $N$. benthamiana, and A. thaliana to very weak in carrot. No viral DNA forms were detected in agroinoculated flossflower, tobacco, or tomato (data not shown). In addition to unit-length ss and dsDNA forms, some samples contained additional viral DNA forms. Most notably, infected A. thaliana contained a viral DNA form with electrophoretic mobility greater than that of unit-length ssDNA. This DNA form likely represents defective viral DNA in which a portion of the viral genome has been deleted. Faintly hybridizing defective DNA appears in other hosts experimentally inoculated with SCTV (Fig. 3) and in the spinach field isolates (Fig. 1). Defective DNA forms are readily produced de novo by other curtoviruses using cloned DNA inocula $(14,15,46,54)$ and have been found in field samples of other curtoviruses (47). Agroinoculated sugar beet and pumpkin also contained a viral DNA form with electrophoretic mobility less than that of OC DNA (Fig. 3). This viral DNA form was assumed to be tandemly repeated viral genomes that could be produced if cleavage and joining of nascent ssDNA did not occur after a single round of rolling-circle replication.

Curtovirus sequence identity and phylogenetics. Comparison of complete nucleotide sequences among curtoviruses (Table 2) indicated that SCTV shared greatest nucleotide sequence identity $(83.9 \%)$ with BSCTV and least nucleotide sequence identity $(64.2 \%)$ with HrCTV. Analysis of individual genes (Table 2) indicated that greater sequence identity between SCTV and BSCTV, relative to other curtoviruses, was due primarily to elevated nucleotide sequence identity of the overlapping $C l$ and $C 4$ genes. C2 gene comparisons revealed that SCTV was nearly equidistant from other curtoviruses (excluding HrCTV which lacks the homologous gene) in nucleotide sequence identity.

TABLE 1. Experimental host range of Spinach curly top virus as determined by agroinoculation of cloned DNA

\begin{tabular}{|c|c|c|}
\hline Host plant & Infectivity $^{\mathrm{a}}$ & Symptoms \\
\hline \multicolumn{3}{|l|}{ Chenopodiaceae } \\
\hline Spinach cv. Indian Summer & $8 / 18$ & Young leaves extremely curled, rigid, deformed and chlorotic; plants stunted \\
\hline Spinach cv. Bloomsdale & $5 / 14$ & Young leaves extremely curled, rigid, deformed and chlorotic; plants stunted \\
\hline Spinach cv. Viroflay & $24 / 31$ & Young leaves extremely curled, rigid, deformed and chlorotic; plants stunted \\
\hline Sugar beet & $21 / 30$ & Leaf margins rolled upward, wrinkled, lower surface rough; veins swollen, cleared \\
\hline \multicolumn{3}{|l|}{ Apiaceae } \\
\hline Carrot & $2 / 24$ & Shoots dwarfed \\
\hline \multicolumn{3}{|l|}{ Asteraceae } \\
\hline Flossflower & $0 / 6$ & None \\
\hline \multicolumn{3}{|l|}{ Brassicaceae } \\
\hline Arabidopsis thaliana & $48 / 48$ & Inflorescence curled, stunted; leaves curled upward; plants dwarfed \\
\hline \multicolumn{3}{|l|}{ Cucurbitaceae } \\
\hline Pumpkin & $2 / 5$ & Young leaves curl downward, reduced in size; flower buds fail to mature; plants stunted \\
\hline \multicolumn{3}{|l|}{ Fabaceae } \\
\hline Bean & $3 / 18$ & Young trifoliolate leaves with curled leaflets; veins swollen; upper leaf surfaces crinkled \\
\hline \multicolumn{3}{|l|}{ Solanaceae } \\
\hline Nicotiana benthamiana & $25 / 36$ & Young leaves upwardly rolled and dwarfed; veins swollen, distorted, and thickened with enations; plants stunted \\
\hline Samsun tobacco & $0 / 24$ & None \\
\hline Tomato & $0 / 6$ & None \\
\hline
\end{tabular}

${ }^{a}$ Number plants infected/number plants inoculated. Data represents the pooled results of two experiments (three experiments for spinach). 
SCTV C3 shared slightly greater nucleotide and amino acid sequence identity with BMCTV, compared with BCTV or BSCTV (again, excluding HrCTV which lacks C3). BCTV, BMCTV, and BSCTV have very similar virion-sense genes that vary between species by less than $4 \%$ nucleotide sequence identity $(43,45,48)$. In contrast, the virion-sense genes of SCTV shared less nucleotide sequence identity ( $\approx 81$ to $82 \%$ [VI], $\approx 84$ to $85 \%$ [V2], and $\approx 89$ to $90 \%$ [V3]) with BCTV, BMCTV, and BSCTV. The lower nucleotide and amino acid sequence identities of each SCTV gene compared with HrCTV was similar to that for comparisons between HrCTV and other curtoviruses (23).

Phylogenetic relationships of SCTV relative to other geminiviruses are depicted for individual genes in Figure 4. Maximum

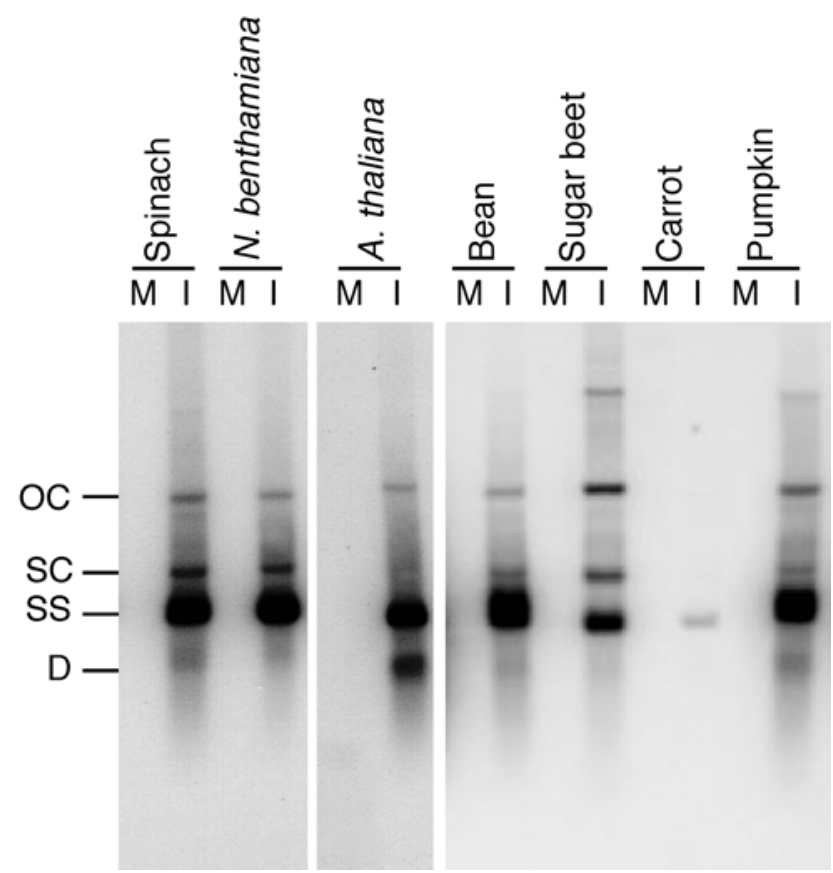

Fig. 3. Viral DNA forms present in experimental hosts agroinoculated with cloned Spinach curly top virus (SCTV) DNA. Presented are Southern blot hybridization assays of total DNA extracts $(2 \mu \mathrm{g})$ from mock-inoculated (M) or SCTV-infected (I) plants hybridized with a ${ }^{32} \mathrm{P}$-labeled SCTV DNA probe. The relative mobility of viral single-stranded (SS) or double-stranded supercoiled (SC) and open circle (OC) DNA forms are indicated on the left. The DNA form present in some infected plant samples and having electrophoretic mobility greater than that of viral SS DNA represents de novo generated defective (D) DNA forms of the viral genome in which portions of the genome have been deleted. DNA forms with electrophoretic mobility slower than that of OC DNA present in infected sugar beet and pumpkin samples may represent de novo generated greater than unit-length viral DNA. Southern blot hybridization assays of samples extracted from spinach, Nicotiana benthamiana, and Arabidopsis thaliana were developed using Xray film (48-h exposure). Southern blot hybridization assays of the remaining samples were developed using a phospho-imager (10-day exposure). likelihood analyses indicated that the virion-sense genes of SCTV are distinct from those of other curtoviruses, such that SCTV appeared in each phylogram in the same position relative to HrCTV and the node common to BCTV, BMCTV, and BSCTV. Minor differences in topology of the virion-sense gene phylograms with respect to BCTV, BSCTV, and BMCTV most likely reflect the limited number of informative sites available within these highly conserved sequences. Phylogenetic relationships of the SCTV complementary-sense genes were incongruent. The SCTV $C l$ and $C 4$ genes shared a node in common with BSCTV, whereas the SCTV $C 2$ and $C 3$ genes shared a node in common with BMCTV. Similar relationships among curtovirus genes were observed (data not shown) using neighbor-joining and parsimony methods (58).

Identification of potential recombination sites. Three sequence junctions representing sites of potential recombination among curtoviruses were identified. One sequence junction was located in the large intergenic region between SCTV nucleotides 251 and 252. The second junction was located between SCTV nucleotides 1,278 and 1,344. These two putative recombination sites essentially flank the virion-sense genes. The third junction was located between SCTV nucleotides 2,416 and 2,483 in the central region of the $C l$ gene, near the termination codon of the C4 gene.

\section{DISCUSSION}

SCTV is a new curtovirus species. Complete genome comparisons among curtoviruses revealed that SCTV was most closely related to BSCTV ( $\approx 84 \%$ nucleotide sequence identity). This value is slightly higher than that of pairwise comparisons (79 to $83 \%$ nucleotide sequence identity) among BCTV, BSCTV, and BMCTV (52) but below the curtovirus species demarcation threshold of $89 \%$ recently established by the Geminiviridae Working Group of the International Committee on the Taxonomy of Viruses in the upcoming 8th Report (41). Therefore, we propose that the curtovirus isolated from spinach and described in this report represents a new species designated as Spinach curly top virus.

Among 58 curtovirus field isolates recovered mostly from sugar beet in eight U.S. states during 1994 and 1995 (47,51), none had endonuclease restriction maps similar to that of SCTV from southwest Texas. This suggests that SCTV either has a restricted geographic distribution or was uncommon in (or absent from) the sugar beet production fields sampled. Given that BSCTV and BMCTV are widely distributed throughout the western United States $(47,51)$ and have wide host ranges that include spinach (49), more than one curtovirus species may cause curly top disease of spinach in the field. Whether other curtoviruses, in addition to SCTV, contributed to the 1996 southwest Texas curly top disease epidemic was not determined because only 3 of the 46 curtovirus-positive samples were characterized in sufficient detail to permit species identification.

TABLE 2. Percent sequence identity of Spinach curly top virus relative to Curtovirus species Beet curly top virus (BCTV), Beet severe curly top virus (BSCTV), Beet mild curly top virus (BMCTV), and Horseradish curly top virus (HrCTV)

\begin{tabular}{|c|c|c|c|c|c|c|c|c|}
\hline \multirow[b]{2}{*}{ Virus } & \multirow[b]{2}{*}{ Complete genome } & \multicolumn{7}{|c|}{ Individual gene ${ }^{\mathrm{a}}$} \\
\hline & & $V 1$ & $V 2$ & $V 3$ & $C 1$ & $C 2$ & $C 3$ & $C 4$ \\
\hline BCTV-Cal & 75.9 & $81.0(85.8)$ & $85.3(81.4)$ & $89.0(86.4)$ & $72.3(71.5)$ & $75.5(57.9)$ & $72.3(65.4)$ & $70.6(43.5)$ \\
\hline BCTV-Logan & 76.0 & $81.4(86.6)$ & $85.3(81.4)$ & $89.0(86.4)$ & $72.8(71.8)$ & $74.5(55.7)$ & $71.6(66.9)$ & $71.0(43.5)$ \\
\hline BSCTV-CFH & 83.9 & $81.6(86.6)$ & $84.3(79.5)$ & $89.8(87.5)$ & $86.6(86.7)$ & $75.7(59.3)$ & $72.1(68.4)$ & $96.1(94.1)$ \\
\hline BSCTV-Iran & 83.9 & $81.3(86.2)$ & $84.0(77.8)$ & $89.7(87.4)$ & $86.7(87.0)$ & $75.7(60.0)$ & $71.8(66.9)$ & $96.1(94.1)$ \\
\hline BMCTV-Worland & 78.8 & $82.1(86.2)$ & $85.2(80.3)$ & $89.8(86.4)$ & $78.0(80.5)$ & $76.4(59.2)$ & $75.0(71.3)$ & $70.2(47.1)$ \\
\hline BMCTV-W4 & 78.7 & $81.8(86.2)$ & $85.2(80.3)$ & $90.2(87.5)$ & $78.0(80.2)$ & $76.6(61.9)$ & $74.5(69.1)$ & $70.6(48.2)$ \\
\hline HrCTV & 64.2 & $81.5(84.9)$ & $80.3(71.8)$ & $83.7(76.1)$ & $57.3(54.7)$ & ND & ND & $47.8(16.5)$ \\
\hline
\end{tabular}

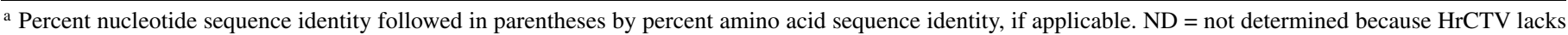
the homologous gene. 

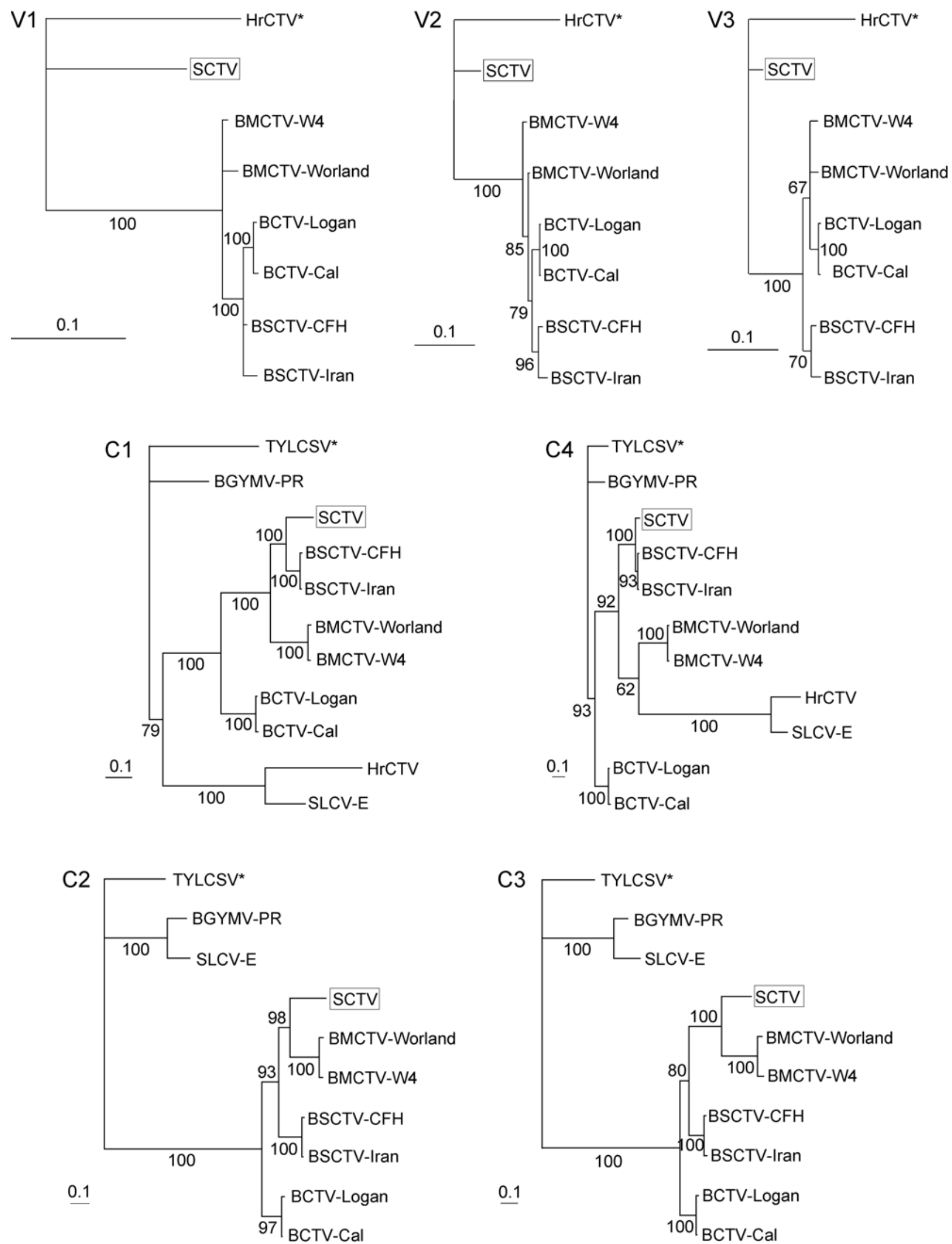

Fig. 4. Phylogenetic relationships of Spinach curly top virus (SCTV) with select geminiviruses. Presented are maximum likelihood phylograms for each virionsense gene $(V 1, V 2$, and $V 3)$ and for each complementary-sense gene $(C 1, C 2, C 3$, and $C 4)$. The relative position of SCTV in each phylogram is indicated by a box. Clade credibility values are listed for nodes having a minimum of $60 \%$ support. Nodes with clade credibility values less than $60 \%$ were collapsed to polytomies. Taxa used to root each tree are indicated by an asterisk. Scale bar for each phylogram indicates length of horizontal branches corresponding to 0.1 substitution/nucleotide. Acronyms for Curtovirus spp. compared are Beet curly top virus (BCTV), Beet severe curly top virus (BSCTV), Beet mild curly top virus (BMCTV), and Horseradish curly top virus (HrCTV). Acronyms for Begomovirus spp. included in complementary-sense gene comparisons are Bean golden yellow mosaic virus-PR (BGYMV-PR), Squash leaf curl virus-E (SLCV-E), and Tomato yellow leaf curl Sardinia virus (TYLCSV). 
Incongruent gene phylogenies suggest recombination among curtovirus lineages. The three potential recombination sites identified are consistent with the incongruent gene phylogenies depicted in Figure 4. Two of the sequence junctions (located between SCTV nucleotides 251 and 252 and nucleotides 1,278 and 1,344) flank the virion-sense genes, suggesting that these three genes were inherited as a unit. The position of the third potential recombination site (located between SCTV nucleotides 2,416 and 2,483) suggests that the $C 4$ gene, the 5 '-proximal half of the $C l$ gene, and the ori share common ancestry such that the cis- and trans-acting curtovirus replication specificity elements $(5,6)$ of each genome were derived from the same lineage. Given this relationship, it is not surprising that the SCTV cis-acting specificity element (the Rep binding site GGTGCTTTGGGAG) is very similar to that of BSCTV (GGTGCTTTGGGTG). The fact that the genomic fragment containing the $C 2$ and $C 3$ genes has one potential recombination site near the $3^{\prime}$ end of the $C 3$ gene and the other potential recombination site upstream of the $C 2$ initiation codon suggests that these two genes were inherited as a unit that also included the $3^{\prime}$ proximal portion of the $C l$ gene. Apparently, a chimeric $C l$ gene is tolerated not only in experimentally generated curtovirus recombinants $(5,53)$ but also in naturally occurring curtovirus genomes.

Although incongruent phylogenetic relationships of individual curtovirus genes are most easily explained as the result of recombination among curtovirus lineages, the analysis does not identify which extant curtovirus genomes represent ancestral (nonrecombinant) or derived (recombinant) lineages. There are multiple and equally plausible scenarios in which SCTV represents a lineage derived by recombination. However, it is equally plausible that the lineage represented by SCTV was not generated by recombination. For example, the SCTV lineage could have served as a donor of the ori-C1-C4 sequences acquired by an ancestor of BSCTV and as a donor of the C2-C3 sequences acquired by an ancestor of BMCTV. In this scenario, it is not SCTV but BSCTV and BMCTV that represent lineages generated by recombination.

In addition to the curtovirus examples described here, other geminiviruses may have recombinant origins $(2,10,32,34,38,60)$. Recombination has been demonstrated experimentally in which reassortment of the DNA A and B components of two begomoviruses resulted in the common region (containing the ori) of the DNA A component replacing that of the heterologous DNA B component (19). Limited experimental evidence for recombination among curtoviruses also exists, in that some wild-type progeny DNA was generated in systemically infected plants following co-inoculation with complementing $\mathrm{C} 1$ (replication deficient) and V1 (movement deficient) mutants of BCTV-Cal (4). Although geminiviruses replicate by a rolling circle mechanism $(39,53)$, recent studies with the begomovirus Abutilon mosaic virus indicate that an alternative recombination-dependent means of replication also may be employed $(22,36)$. Collectively, the evidence for recombination among both begomoviruses and curtoviruses is compelling, such that recombination may be viewed as a significant factor in geminivirus evolution.

\section{ACKNOWLEDGMENTS}

This work was, in part, funded by an NIH/MBRS/SCORE Grant (GM08194). Mention of proprietary or brand names are necessary to report factually on available data; however, the USDA neither guarantees nor warrants the standard of the product, and the use of the name by USDA implies no approval to the exclusion of others that also may be suitable. We thank J. L. Sunter and C. L. Tyszko for technical assistance.

\section{LITERATURE CITED}

1. Bennett, C. W. 1971. The curly top disease of sugarbeet and other plants. Monogr. 7. The American Phytopathological Society, St. Paul, MN.
2. Briddon, R. W., Bedford, I. D., Tsai, J. H., and Markham, P. G. 1996. Analysis of the nucleotide sequence of the treehopper-transmitted geminivirus, tomato pseudo-curly top virus, suggests a recombinant origin. Virology 219:387-394.

3. Briddon, R. W., Stenger, D. C., Bedford, I. D., Stanley, J., Izadpanah, K., and Markham, P. G. 1998. Comparison of a beet curly top virus isolate originating from the old world with those from the new world. Eur. J. Plant Pathol. 104:77-84.

4. Briddon, R. W., Watts, J., Markham, P. G., and Stanley, J. 1989. The coat protein of beet curly top virus is essential for infectivity. Virology 172:628-633.

5. Choi, I.-R., and Stenger, D. C. 1995. Strain-specific determinants of beet curly top virus DNA replication. Virology 206:904-912.

6. Choi, I.-R., and Stenger, D. C. 1996. The strain-specific cis-acting element of beet curly top geminivirus DNA replication maps to the directly repeated motif of the ori. Virology 226:122-126.

7. Correll, J. C., Morelock, T. E., Black, M. C., Koike, S. T., Brandenberger, L. P., and Dainello, F. J. 1994. Economically important diseases of spinach. Plant Dis. 78:653-660.

8. Duffus, J. E., Milbrath, G. M., and Perry, R. 1982. Unique type of curly top virus and its relationship with horseradish brittle root. Plant Dis. 66:650-652.

9. Duffus, J. E., and Skoyen, I. O. 1977. Relationship of age of plants and resistance to a severe isolate of beet curly top virus. Phytopathology 67:151-154.

10. Fondong, V. N., Pita, J. S., Rey, M. E. C., de Kochko, A., Beachy, R. N., and Fauquet, C. M. 2000. Evidence of synergism between African cassava mosaic virus and a new double-recombinant geminivirus infecting cassava in Cameroon. J. Gen. Virol. 81:287-297.

11. Fontes, E. P. B., Eagle, P. A., Sipe, P. S., Luckow, V. A., and HanleyBowdoin, L. 1994. Interaction between a geminivirus replication protein and origin DNA is essential for viral replication. J. Biol. Chem. 269:8459-8465.

12. Fontes, E. P. B., Gladfelter, H. J., Schaffer, R. L., Petty, I. T. D., and Hanley-Bowdoin, L. 1994. Geminivirus replication origins have a modular organization. Plant Cell 6:405-416.

13. Frischmuth, S., Frischmuth, T., Latham, J. R., and Stanley, J. 1993. Transcriptional analysis of the virion-sense genes of the geminivirus beet curly top virus. Virology 197:312-319.

14. Frischmuth, T., and Stanley, J. 1992. Characterization of a beet curly top virus subgenomic DNA localizes sequences required for replication. Virology 189:808-811.

15. Frischmuth, T., and Stanley, J. 1994. Beet curly top virus symptom amelioration in Nicotiana benthamiana transformed with a naturally occurring subgenomic DNA. Virology 200:826-830.

16. Holmes, E. C., Worobey, M., and Rambaut, A. 1999. Phylogenetic evidence for recombination in Dengue virus. Mol. Biol. Evol. 16:405-409.

17. Hormuzdi, S. G., and Bisaro, D. M. 1993. Genetic analysis of beet curly top virus: evidence for three virion sense genes involved in movement and regulation of single- and double-stranded DNA levels. Virology 193:900-909.

18. Hormuzdi, S. G., and Bisaro, D. M. 1995. Genetic analysis of beet curly top virus: Examination of the roles of L2 and L3 genes in viral pathogenesis. Virology 206:1044-1054.

19. Hou, Y. M., and Gilbertson, R. L. 1996. Increased pathogenicity in a pseudorecombinant bipartite geminivirus correlates with intermolecular recombination. J. Virol. 70:5430-5436.

20. Hoyle, B. J. 1977. Curly top identification handbook. Univ. Calif. Div. Agric. Sci. Publ. No. 4079.

21. Huelsenbeck, J. P., and Ronquist, F. 2001. MRBAYES: Bayesian inference of phylogenetic trees. Bioinformatics 17:754-755.

22. Jeske, H., Lütgemeier, M., and Preiss, W. 2001. Distinct DNA forms indicate rolling circle and recombination-dependent replication of Abutilon mosaic geminivirus. EMBO J. 20:6158-6167.

23. Klute, K. A., Nadler, S. A., and Stenger, D. C. 1996. Horseradish curly top is a distinct subgroup II geminivirus species with rep and $C 4$ genes derived from a subgroup III ancestor. J. Gen. Virol. 77:1369-1378.

24. Kumar, S., Tamura, K., Jakobsen, I. B., and Nei, M. 2001. MEGA2: Molecular Evolutionary Genetics Analysis software. Bioinformatics 17:1244-1245.

25. Latham, J. R., Saunders, K., Pinner, M. S., and Stanley, J. 1997. Induction of plant cell division by beet curly top virus gene C4. Plant J. 11:12731283.

26. Laufs, J., Traut, W., Heyraud, F., Matzeit, V., Rogers, S. G., Schell, J., and Gronenborn, B. 1995. In vitro cleavage and joining at the viral origin of replication by the replication initiator protein of tomato yellow leaf curl virus. Proc. Natl. Acad. Sci. USA 92:3879-3883.

27. Lazarowitz, S. G., and Lazdins, I. B. 1991. Infectivity and complete nucleotide sequence of the cloned genomic components of a bipartite squash leaf curl geminivirus with a broad host range. Virology 180:58-69. 
28. Lee, S., Stenger, D. C., Bisaro, D. M., and Davis, K. R. 1994. Identification of loci in Arabidopsis that confer resistance to geminivirus infection. Plant J. 6:525-535.

29. Martin, E. C., and Rybicki, E. 2000. RDP: Detection of reccombination amongst aligned sequences. Bioinformatics 16:562-563.

30. McLean, D. M., Webb, R. E., and Perry, B. A. 1965. Virus disease symptoms of spinach in the Lower Rio Grande Valley. Tex. Agric. Exp. Stn. Bull. MP-775.

31. Notredame, C., Higgins, D. G., and Heringa, J. 2000. T-Coffee: A novel method for fast and accurate multiple sequence alignment. J. Mol. Biol. 302:205-217.

32. Padidam, M., Sawyer, S., and Fauquet, C. M. 1999. Possible emergence of new geminiviruses by frequent recombination. Virology 265:218-225.

33. Page, R. D. M. 1996. TREEVIEW: An application to display phylogenetic trees on personal computers. Comput. Appl. Biosci. 12:357-358.

34. Pita, J. S., Fondong, V. N., Sangare, A., Otim-Nape, G. W., Ogwal, S., and Fauquet, C. M. 2001. Recombination, pseudorecombination and synergism of geminiviruses are determinant keys to the epidemic of severe cassava mosaic disease in Uganda. J. Gen. Virol. 82:655-665.

35. Posada, D., and Crandall, K. A. 1998. MODELTEST: Testing the model of DNA substitution. Bioinformatics 14:817-818.

36. Preiss, W., and Jeske, H. 2003. Multitasking in replication is common among geminiviruses. J. Virol. 77:2972-2980.

37. Rogers, S. G., Klee, H. J., Horsch, R. B., and Fraley, R. T. 1987. Improved vectors for plant transformation: Expression cassette vectors and new selectable markers. Methods Enzymol. 153:253-277.

38. Sanz, A. I., Fraile, A., Garcia-Arenal, F., Zhou, X. P., Robinson, D. J., Khalid, S., Butt, T., and Harrison, B. D. 2000. Multiple infection, recombination and genome relationships among begomovirus isolates found in cotton and other plants in Pakistan. J. Gen. Virol. 81:1839-1849.

39. Saunders, K., Lucy, A., and Stanley, J. 1991. DNA forms of the geminivirus African cassava mosaic virus consistent with a rolling circle mechanism of replication. Nucleic Acids Res. 19:2325-2330.

40. Soto, M. J., and Gilbertson, R. L. 2003. Distribution and rate of movement of the curtovirus Beet mild curly top virus (family Geminiviridae) in the beet leafhopper. Phytopathology 93:478-484.

41. Stanley, J., Bisaro, D. M., Briddon, R. W., Brown, J. K., Fauquet, C. M., Harrison, B. D., Rybicki, E. P., and Stenger, D. C. Family Geminiviridae. In: Virus Taxonomy: The Classification and Nomenclature of Viruses. The Eighth Report of the International Committee on Taxonomy of Viruses. Academic Press, San Diego, CA. In press.

42. Stanley, J., and Latham, J. R. 1992. A symptom variant of beet curly top virus produced by mutation of open reading frame C4. Virology 191:396405.

43. Stanley, J., Markham, P. G., Callis, R. J., and Pinner, M. S. 1986. The nucleotide sequence of an infectious clone of the geminivirus beet curly top virus. EMBO J. 5:1761-1767.

44. Stanley, J., Pinner, M. S., Bedford, I., and Markham, P. G. 1992 Mutational analysis of the monopartite geminivirus beet curly top virus. Virology 191:396-405.
45. Stenger, D. C. 1994. Complete nucleotide sequence of the hypervirulent CFH strain of beet curly top virus. Mol. Plant-Microbe Interact. 7:154157.

46. Stenger, D. C. 1994. Strain-specific mobilization and amplification of a transgenic defective-interfering DNA of the geminivirus beet curly top virus. Virology 203:397-402.

47. Stenger, D. C. 1995. Genotypic variability and the occurrence of less than genome-length viral DNA forms in a field population of beet curly top geminivirus. Phytopathology 85:1316-1322.

48. Stenger, D. C. 1998. Replication specificity elements of the Worland strain of beet curly top virus are compatible with those of the CFH strain but not those of the Cal/Logan strain. Phytopathology 88:1174-1178.

49. Stenger, D. C., Carbonaro, D., and Duffus, J. E. 1990. Genomic characterization of phenotypic variants of beet curly top virus. J. Gen. Virol. 71:2211-2215.

50. Stenger, D. C., Davis, K. R., and Bisaro, D. M. 1994. Recombinant beet curly top virus genomes exhibit both parental and novel pathogenic phenotypes. Virology 200:677-685.

51. Stenger, D. C., and McMahon, C. L. 1997. Genetic diversity of beet curly top virus populations in the western United States. Phytopathology 87:737-744.

52. Stenger, D. C., and Ostrow, K. M. 1996. Genetic complexity of a beet curly top virus population used to assess sugar beet cultivar response to infection. Phytopathology 86:1316-1322.

53. Stenger, D. C., Revington, G. N., Stevenson, M. C., and Bisaro, D. M. 1991. Replicational release of geminivirus genomes from tandemly repeated copies: Evidence for rolling-circle replication of a plant viral DNA. Proc. Natl. Acad. Sci. USA 88:8029-8033.

54. Stenger, D. C., Stevenson, M. C., Hormuzdi, S. G., and Bisaro, D. M. 1992. A number of subgenomic DNAs are produced following agroinoculation of plants with beet curly top virus. J. Gen. Virol. 73:237-242.

55. Sunter, G., Hartitz, M. D., and Bisaro, D. M. 1993. Tomato golden mosaic virus leftward gene expression: Autoregulation of geminivirus replication protein. Virology 195:275-280.

56. Sunter, G., Stenger, D. C., and Bisaro, D. M. 1994. Heterologous complementation by geminivirus AL2 and AL3 genes. Virology 203:203-210.

57. Sunter, G., Sunter, J. L., and Bisaro, D. M. 2001. Plants expressing tomato golden mosaic virus AL2 or beet curly top virus L2 transgenes show enhanced susceptibility to infection by DNA and RNA viruses. Virology 285:59-70.

58. Swofford, D. 1997. PAUP*: Phylogenetic Analysis Using Parsimony (* and other methods). Sinauer Associates, Sunderland, MA.

59. Thompson, J. D., Gibson, T. J., Plewniak, F., Jeanmougin, F., and Higgins, D. G. 1997. The ClustalX windows interface: Flexible strategies for multiple sequence alignment aided by quality analysis tools. Nucleic Acids Res. 24:4876-4882.

60. Zhou, X. P., Liu, Y. L., Calvert, L., Munoz, C., Otim-Nape, G. W., Robinson, D. J., and Harrison, B. D. 1997. Evidence that DNA-A of a geminivirus associated with severe cassava mosaic disease in Uganda has arisen by interspecific recombination. J. Gen. Virol. 78:2101-2111. 